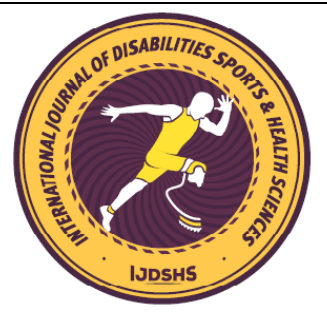

\title{
Comparison of the Supervised and Home-Based Physiotherapy Program in Patients with Lateral Epicondylitis
}

\author{
Raziye ŞAVKIN ${ }^{* 1}$ (D) and Şule ŞİMŞEK ${ }^{2}$ (iD \\ ${ }^{1}$ School of Physical Therapy and Rehabilitation, Pamukkale University, Denizli, Turkey \\ ${ }^{2}$ Saraykoy Vocational School, Department of Therapy and Rehabilitation, Denizli, Turkey \\ *Corresponding author: raziyesavkin@ hotmail.com
}

\begin{abstract}
Objective: This study aimed to compare the effectiveness of a supervised and home-based physiotherapy program in the reduction of pain and in improving functional status and quality of life in patients with lateral epicondylitis. Method: Patients diagnosed with lateral epicondylitis and referred to the physiotherapy clinic were evaluated retrospectively. A total of 32 patients were separated into two groups as supervised and home-based physiotherapy groups. All the patients received standard physiotherapy program consisting of static stretching exercises of the ECRB tendon, eccentric exercises of the wrist extensors and cold application, for 3 weeks. The groups were compared in terms of pain severity, range of motion, functional status (Quick-DASH) and quality of life (SF-36) after treatment. Results: Fifteen patients (12 females, 3 males) with a mean age of $44.20 \pm 7.35$ years were included in the supervised physiotherapy group, and 17 patients (15 females, 2 males) with a mean age of $48.65 \pm 12.33$ years in the home-based physiotherapy group. There was no statistically significant difference in activity $(\mathrm{p}=0.980)$ and rest pain $(\mathrm{p}=0.483)$, wrist flexion $(\mathrm{p}=0.775)$ and extension $(\mathrm{p}=0.838)$ range of motion, functionality $(\mathrm{p}=0.346)$ and quality of life $(\mathrm{p}=0.923)$ between groups. Conclusion: Patients participating in a home-based physiotherapy program had similar clinical outcomes in terms of pain intensity, range of motion, functionality, and quality of life as patients participating in a supervised physiotherapy. Further prospective randomized studies can be conducted by increasing the sample size and comparing with cost analyzes to determine the rehabilitation regimen that will provide the best outcomes in lateral epicondylitis rehabilitation.
\end{abstract}

Keywords

Lateral Epicondylitis, Home Based Physiotherapy, Supervised Physiotherapy, Pain, Function, Quality of Life

\section{INTRODUCTION}

Lateral epicondylitis, also known as Tennis Elbow or Lateral Elbow Tendinopathy, which causes limitation in daily living activities, is one of the most common overuse syndromes in the elbow (Day et al., 2019). As a result of recurrent mechanical overuse or overload, the tendon's ability to repair itself becomes impaired and eventually fails. This then leads to structural alteration (tendon tearing), fibrosis and calcification (Cohen, \& da Rocha Motta Filho, 2015)
Although there is no gender difference in prevalence (Ma \& Wang, 2020) symptoms are more prolonged and severe in women (Waugh et al., 2004). Dominant extremity involvement is common and the extensor carpi radialis brevis (ECRB) is most affected tendon (Alizadehkhaiyat \& Frostick, 2015).

Pain and point tenderness over lateral epicondyle, weak grip strength, functional limitation are typical findings (Brummel et al., 2014). Although it is easy to diagnose, a 
universally accepted treatment regimen has not been defined to date (Vaquero-Picado et al., 2017). However, the therapeutic goals in the treatment of lateral epicondylitis are control of elbow pain, preservation of movement in the affected extremity, improvement in grip strength and endurance, return to normal function, and prevent further histological and clinical deterioration (Ahmad et al., 2013). Conservative treatment including home-based or supervised exercise programs is one of the most recommended physiotherapy modalities for these purposes (Weber et al., 2015).

Home-based regimens can be performed at any time of the day without clinician supervision and include patient visits once or twice a week for further instruction. Supervised regimens are performed every day in the clinic under the supervision of a therapist and are more costly. (Stasinopoulos et al., 2005). The aim of this study was to compare the effectiveness of a supervised and home-based physiotherapy program in the reduction of pain and in improving functional status and quality of life in patients with lateral epicondylitis.

\section{MATERIALS AND METHODS}

Patients diagnosed with lateral epicondylitis in the Orthopaedics and Traumatology Department of a university hospital and referred to the School of Physical Therapy and Rehabilitation for treatment were evaluated retrospectively. The study was approved by the Clinical Research and Ethics Committee of the authors' affiliated institution.

The inclusion criteria were as follows: age older than 18 years, positive diagnosis of lateral epicondylitis, pain or tenderness persisting for at least 8 weeks on the lateral epicondyle, increased pain during resisted wrist extension, grip and supination, patients who included in a supervised or home-based physiotherapy program. Exclusion criteria were as follows: steroid injections at the lateral epicondyle within the last 6 months, receiving treatments such as non-steroidal antiinflammatory drugs or physiotherapy for lateral epicondylitis during the last 2 weeks, comorbid diseases such as rheumatoid arthritis, neurologic or muscular disorders, diagnosed with or treated for cervical radiculopathy or herniation of intervertebral disc, a history of previous injury of the elbow.

Sixty-three patients datas reviewed, and 31 patients were excluded because of not meet inclusion criteria $(n=12)$, being directed to different treatments $(n=12)$, incomplete data $(n=7)$. The final study sample consisted of 32 patients, with 15 in the supervised physiotherapy program group and 17 in the home-based physiotherapy program.

Patients with lateral epicondylitis referred to our clinic received the same exercise program: static stretching exercises of the ECRB tendon (30$45 \mathrm{~s}$ and 3 times before and after the eccentric exercises), slow progressive eccentric exercises of the wrist extensors ( 3 sets of 10 repetitions with 1min rest between sets), cold pack (15 minutes). To reduce the potential for further damage to the affected tissues, it was aimed to perform the exercises gently without or with mild pain. The exercise program was performed for 3 weeks, 5 times per week, either under the supervision of a physiotherapist (supervised physiotherapy group) or at home without supervision (home-based physiotherapy group). In the home exercise group, patients were called to physical therapy clinics to ensure that they understood how to perform the exercises. During these visits, patients' adherence was questioned. In addition, all patients are given a patient education booklet with recommendations such as ergonomics, activity modification technique, activity avoidance or excess, and lifestyle changes.

All evaluations performed after treatment. Demographic (age, gender) and clinical data (body mass index, dominant and affected extremity) of patients were recorded. Visual analogue scale was used to evaluate elbow pain during rest and activity. Wrist flexion/extension range of motion was assessed by universal goniometer. Upper extremity functionality was assessed with Quick Disability of the Arm, Shoulder, and Hand questionnaire (QUICK-DASH) and quality of life with Short Form-36 (SF-36). Quick DASH consists of 11 items to measure physical function and symptoms in people with musculoskeletal disorders of the upper limb. The final score ranges between 0 (no disability) and 100 (most severe disability) (Düger et al., 2006). 
Short Form-36 (SF-36) was used to determine a patient's health-related quality of life. The total score of the questionnaire ranged from 0 to 100 , with a higher score indicating better quality of life (Koçyiğit et al., 1999).

\section{Statistical Analysis}

Statistical analysis was performed using the software package SPSS (Version 21, SPSS Inc, Chicago, IL, United States). Continuous variables (age and BMI) were presented as mean \pm standard deviation, while categorical variables (gender, dominant and affected extremity) were presented as absolute numbers and percentages. The distribution of data was evaluated using the Shapiro Wilk test. Independent Samples t-test for parametric test assumptions (pain level, QUICK-
DASH and SF-36 scores) and Mann-Whitney U Test for non-parametric test assumptions (wrist flexion/extension range of motion) were used for comparison of the groups. The statistical significance level was set as $\mathrm{p}<0.05$.

\section{RESULTS}

Demographic and clinical characteristics of the patients are given in Table 1. The supervised physiotherapy group consisted of 15 patients (mean age, 44.20 years; 12 female and 3 male) and home-based physiotherapy group consisted of 17 patients (mean age, 26.83 years; 15 female and 2 male). $14(93.3 \%)$ patients in the supervised, 13 $(76.5 \%)$ in the home-based physiotherapy group presented dominant extremity injury.

Table 1. Descriptive data of patients

\begin{tabular}{|c|c|c|c|c|}
\hline \multirow[b]{2}{*}{ Variables } & \multicolumn{2}{|c|}{ Supervised group $(n=15)$} & \multicolumn{2}{|c|}{ Home-based group $(\mathrm{n}=17)$} \\
\hline & Min-Maks & $\mathrm{X} \pm \mathrm{SD}$ & Min-Maks & $\mathrm{X} \pm \mathrm{SD}$ \\
\hline Age (year) & $33-57$ & $44.20 \pm 7.35$ & $28-72$ & $48.65 \pm 12.33$ \\
\hline Body mass index $\left(\mathrm{kg} / \mathrm{m}^{2}\right)$ & $17.91-30.86$ & $26.75 \pm 3.08$ & $22.06-31.93$ & $26.83 \pm 2.74$ \\
\hline & $\mathrm{n}$ & $\%$ & $\mathrm{n}$ & $\%$ \\
\hline $\begin{array}{l}\text { Gender } \\
\text { Female } \\
\text { Male }\end{array}$ & $\begin{array}{c}12 \\
3\end{array}$ & $\begin{array}{l}80 \\
20 \\
\end{array}$ & $\begin{array}{c}15 \\
2\end{array}$ & $\begin{array}{l}88.2 \\
11.8 \\
\end{array}$ \\
\hline $\begin{array}{l}\text { Dominant extremity } \\
\text { Right } \\
\text { Left } \\
\end{array}$ & $\begin{array}{c}14 \\
1 \\
\end{array}$ & $\begin{array}{c}93.3 \\
6.7 \\
\end{array}$ & $\begin{array}{c}14 \\
3 \\
\end{array}$ & $\begin{array}{l}82.4 \\
17.6 \\
\end{array}$ \\
\hline $\begin{array}{l}\text { Affected extremity } \\
\text { Dominant } \\
\text { Nondominant }\end{array}$ & $\begin{array}{c}14 \\
1\end{array}$ & $\begin{array}{c}93.3 \\
6.7\end{array}$ & $\begin{array}{c}13 \\
4\end{array}$ & $\begin{array}{l}76.5 \\
23.5\end{array}$ \\
\hline
\end{tabular}

The comparison of clinical outcome scores of the groups are shown in Table 2. There was no statistically significant difference in activity $(\mathrm{p}=0.980)$ and rest pain $(\mathrm{p}=0.483)$, wrist flexion

\section{DISCUSSION}

This study was planned to compare the effectiveness of a supervised and home-based physiotherapy program in the reduction of pain and in improving functional status and quality of life in patients with lateral epicondylitis. According to the results of this study, home-based physiotherapy is as beneficial as supervised physiotherapy in terms of pain, wrist range of motion, physical function, and quality of life outcomes. $(\mathrm{p}=0.775)$ and extension $(\mathrm{p}=0.838)$ range of motion, functionality $(\mathrm{p}=0.346)$ and quality of life $(\mathrm{p}=0.923)$ between groups.

Eccentric strengthening and static stretching exercises are among the most commonly used conservative techniques in the treatment of lateral elbow tendinopathy (Manias \& Stasinopoulos (2006; Martinez-Silvestrini et al, 2005; Wen et al., 2011). Although there are conflicting results about which of the eccentric strengthening and static stretching exercises are more effective (MartinezSilvestrini et al, 2005; Svernlöv \& Adolfsson 2001), it is recommended that both be included in 
the treatment program in the rehabilitation of tendinopathies (Dimitrios 2016; Dimitrios \& Manias 2013). In present study, eccentric strengthening and static stretching exercises were applied to both groups, and patient outcomes were improved without any difference between the groups.

Table 2. Comparison of the groups in terms of pain, range of motion, function, and quality of life

\begin{tabular}{|c|c|c|c|c|c|}
\hline \multirow[b]{2}{*}{ Variables } & \multicolumn{2}{|c|}{ Supervised group $(n=15)$} & \multicolumn{2}{|c|}{ Home-based group $(n=17)$} & \multirow[b]{2}{*}{$\mathrm{p}$} \\
\hline & $\begin{array}{l}\text { Min- } \\
\text { Max }\end{array}$ & $\begin{array}{c}\text { Mean } \pm \text { SD } \\
(\text { Median) }\end{array}$ & Min-Max & $\begin{array}{c}\text { Mean } \pm \text { SD } \\
(\text { Median) }\end{array}$ & \\
\hline Pain-rest & $2-7$ & $\begin{array}{c}3.87 \pm 1.41 \\
(4) \\
\end{array}$ & $0.00-7.5$ & $\begin{array}{c}3.88 \pm 2.03 \\
(4) \\
\end{array}$ & 0.980 \\
\hline Pain-activity & $4-9$ & $\begin{array}{c}6.67 \pm 1.72 \\
(6) \\
\end{array}$ & $4.5-9.5$ & $\begin{array}{c}7.06 \pm 1.34 \\
(7) \\
\end{array}$ & 0.483 \\
\hline Flexion & $80-90$ & $\begin{array}{c}85.53 \pm 4.44 \\
(86)\end{array}$ & $80-90$ & $\begin{array}{c}85.87 \pm 4.98 \\
(90)\end{array}$ & 0.775 \\
\hline Extension & $65-70$ & $\begin{array}{c}69.07 \pm 1.71 \\
(70) \\
\end{array}$ & $65-70$ & $\begin{array}{c}69.07 \pm 1.75 \\
(70) \\
\end{array}$ & 0.838 \\
\hline QUICK-DASH & $2.25-59$ & $\begin{array}{c}32.08 \pm 17.13 \\
(36.25)\end{array}$ & $\begin{array}{l}13.15- \\
63.75 \\
\end{array}$ & $\begin{array}{c}37.32 \pm 13.18 \\
(36.25)\end{array}$ & 0.346 \\
\hline SF-36 physical & $29-100$ & $\begin{array}{c}66.27 \pm 22.82 \\
(57) \\
\end{array}$ & $29-71$ & $\begin{array}{c}56.18 \pm 11.84 \\
(57) \\
\end{array}$ & 0.139 \\
\hline SF-36 mental & $24-100$ & $\begin{array}{c}64.73 \pm 24.02 \\
(62) \\
\end{array}$ & $38-100$ & $\begin{array}{c}67.29 \pm 17.58 \\
(67) \\
\end{array}$ & 0.736 \\
\hline SF-36 total & $23-100$ & $\begin{array}{c}62.07 \pm 21.48 \\
(69)\end{array}$ & $46-80$ & $\begin{array}{c}61.47 \pm 10.39 \\
(57)\end{array}$ & 0.923 \\
\hline
\end{tabular}

Min: Minimum, Max: Maximum, X: Mean, SD: Standard Deviation, QUICK-DASH: Quick Disability of the Arm, Shoulder, and Hand questionnaire, SF-36: Short Form-36

Home-based and supervised exercise can be equally effective on patient clinical outcomes in musculoskeletal disorders (Gutiérrez-Espinoza et al., 2020; Granviken \& Vasseljen., 2015). Homebased exercises can also improve pain, muscle strength, functionality, and quality of life in patients with lateral epicondylitis (MartinezSilvestrini et al, 2005; Peterson et al., 2014; Svernlöv \& Adolfsson, 2001; Wen et al., 2011). Dimitrios and Manias reported that a supervised exercise program was more effective than homebased exercise in reducing pain and improving function. However, different exercise protocols were applied to the groups (Dimitrios \& Manias 2013). In the present study, the same treatment program was applied to both groups for 3 weeks, and the outcomes of the supervised physiotherapy program were similar to those of the home-based. Based on these findings home-besed physiotherapy may be preferred in patients with lateral epicondylitis.

The success of exercise interventions largely depends on patient adherence. Dimitrios and
Manias stated that patients who underwent home exercise program did not comply with the exercise regimen (Dimitrios and Manias., 2013). In this study, we questioned the exercise compliance of the home-based group during weekly clinical visits, and we did not observe non-compliance. Our study duration was relatively short. In longterm follow-up studies, mobile health technologies, self-monitoring and patient education can be used to increase patient compliance of home-based exercise programs (Argent et al, 2018).

Both groups had moderate activity pain and healthrelated quality of life after treatment. The shortterm implementation of both exercise programs may not have provided sufficient reduction in pain intensity. Although the positive effect of exercise for tendinopathy has been proven, the evidence for optimal dosing and loading strategy is insufficient (van Ark et al. 2016). There is also a relationship between pain and quality of life (Samagh et al, 2015). The moderate level of pain severity of our 
participants may have caused the health-related quality of life scores to be moderate.

This study has some limitations. The main limitations of this study are that it was a nonrandomized study and absence of pretreatment evaluations. The other limitation of our study is that follow-up duration is very short. In future randomized controlled trials, a longer follow-up period and sample size may be important to gain more information on the effectiveness of exercise methods.

In conclusion, this study showed that for patients with lateral epicondylitis, patients participating in a home-based physiotherapy program had similar clinical outcomes in terms of pain intensity, range of motion, functionality, and quality of life as patients participating in a supervised physiotherapy. Further prospective randomized studies can be conducted by increasing the sample size and comparing with cost analyzes to determine the rehabilitation regimen that will provide the best outcomes in lateral epicondylitis rehabilitation.

\section{Conflict of interests:}

The authors have no conflict of interests to declare. No financial support was received for this study.

\section{Ethics Statement}

The studies involving human participants were reviewed and approved by the Pamukkale University, Non-Interventional Clinic Research Ethics Committee (Date: 13.07.2021; Decision / Protocol number: E-60116787-020-77774). Written informed consent to participate in this study was provided by the patients/participants.

\section{REFERENCES}

Ahmad, Z., Siddiqui, N., Malik, S. S., AbdusSamee, M., Tytherleigh-Strong, G., \& Rushton, N. (2013). Lateral epicondylitis: a review of pathology and management. The Bone \& Joint Journal, 95-B(9), 1158-1164. Doi:10.1302/0301-620x.95b9.29285

Alizadehkhaiyat, O., \& Frostick, S. P. (2015). Electromyographic assessment of forearm muscle function in tennis players with and without Lateral Epicondylitis. Journal of Electromyography and Kinesiology, 25(6), 876-886. Doi.1016/j.jelekin.2015.10.013
Argent, R., Daly, A., \& Caulfield, B. (2018). Patient Involvement with Home-Based Exercise Programs: Can Connected Health Interventions Influence Adherence? JMIR mHealth and uHealth, 6(3), e47. Doi: 10.2196/mhealth.8518

Brummel, J., Baker, C. L., 3rd, Hopkins, R., \& aker, C. L., Jr (2014). Epicondylitis: lateral. Sports Medicine and Arthroscopy Review, 22(3),e1-e6.Doi:10.1097/JSA.00000000000 00024

Cohen, M., \& da Rocha Motta Filho, G. (2015). Lateral Epicondylitis of The Elbow. Revista Brasileira de Ortopedia, 47(4), 414-420. Doi:10.1016/S2255-4971(15)30121-X

Day, J. M., Lucado, A. M., \& Uhl, T. L. (2019). A Comprehensive Rehabilitation Program for Treating Lateral Elbow Tendinopathy. International Journal of Sports Physical Therapy, 14(5), 818-829.

Dimitrios S. (2016). Lateral Elbow Tendinopathy: Evidence of Physiotherapy

Management. World Journal of Orthopedics, 7(8), 463-466. Doi: 10.5312/wjo.v7.i8.463

Dimitrios, S. \& Manias, P. (2013). Comparing Two Exercise Programmes for the Management of Lateral Elbow Tendinopathy (Tennis Elbow/Lateral Epicondylitis)-A Controlled Clinical Trial. The Open Access Journal of Science and Technology, 1: 1-8. DOI: 10.11131/2013/100013

Düger, T., Yakut, E., Öksüz, Ç., Yörükan, S., Semin Bilgütay, B., Ayhan, Ç., Leblebicioğlu, G., Kayıhan, H., Kırdı, N., Yakut, Y., Güler, Ç. (2006). Reliability and Validity of the Turkish Version of the Disabilities of the Arm, Shoulder and Hand (DASH) Questionnaire. Physiotherapy Rehabilitation, 17(3);99-107.

Granviken, F., \& Vasseljen, O. (2015). Home Exercises and Supervised Exercises Are Similarly Effective for People with Subacromial Impingement: A Randomised Trial. Journal of Physiotherapy, 61(3), 135141. Doi: 10.1016/j.jphys.2015.05.014

Gutiérrez-Espinoza, H., Araya-Quintanilla, F., Cereceda-Muriel, C., Álvarez-Bueno, C., Martínez-Vizcaíno, V., \& Cavero-Redondo, I. (2020). Effect of Supervised Physiotherapy Versus Home Exercise Program in Patients with Subacromial 
Impingement Syndrome: A Systematic Review and Meta-Analysis. Physical Therapy in Sport, 41, 34-42. Doi: 10.1016/j.ptsp.2019.11.003

Koçyiğit, H., Aydemir, Ö., Ölmez, N. ve Memiş, A. (1999). Reliability and Validity of the Turkish Version of Short Form-36 (SF36). Journal of Medicine and Treatment, 12(2), 102-106.

Ma, K. L., \& Wang, H. Q. (2020). Management of Lateral Epicondylitis: A Narrative Literature Review. Pain Research \& Management, 2020, 6965381. Doi:10.1155/2020/6965381

Manias, P., \& Stasinopoulos, D. (2006). A Controlled Clinical Pilot Trial to Study the Effectiveness of Ice as a Supplement to the Exercise Programme for the Management of Lateral Elbow Tendinopathy. British Journal of Sports Medicine, 40(1), 81-85. Doi:10.1136/bjsm.2005.020909

Martinez-Silvestrini, J. A., Newcomer, K. L., Gay, R. E., Schaefer, M. P., Kortebein, P., \& Arendt, K. W. (2005). Chronic Lateral Epicondylitis: Comparative Effectiveness of a Home Exercise Program Including Stretching Alone Versus Stretching Supplemented with Eccentric or Concentric Strengthening. Journal of Hand Therapy: Official Journal of the American Society of Hand Therapists, 18(4), 411-420. Doi: 10.1197/j.jht.2005.07.007

Peterson, M., Butler, S., Eriksson, M., \& Svärdsudd, K. (2014). A Randomized Controlled Trial of eccentric vs. Concentric Graded Exercise in Chronic Tennis Elbow (Lateral Elbow Tendinopathy). Clinical Rehabilitation, 28(9), 862-872. Doi: $10.1177 / 0269215514527595$

Samagh, P., Sudhakar, K., \& Jindal, R. (2015). The Impact of Lateral Epicondylitis On Quality of Life. International Journal of Physiotherapy, 2, 627-632.

Stasinopoulos, D., Stasinopoulou, K., \& Johnson, M. I. (2005). An Exercise Programme for the management of Lateral Elbow Tendinopathy. British Journal of Sports Medicine, 39(12), 944-947. Doi:10.1136/bjsm.2005.019836
Svernlöv, B., \& Adolfsson, L. (2001). Nonoperative Treatment Regime Including Eccentric Training for Lateral Humeral Epicondylalgia. Scandinavian Journal of Medicine \& Science in Sports, 11(6), 328334. Doi: 10.1034/j.16000838.2001.110603.x

van Ark, M., Cook, J. L., Docking, S. I., Zwerver, J., Gaida, J. E., van den Akker-Scheek, I., \& Rio, E. (2016). Do isometric and isotonic exercise programs reduce pain in athletes with patellar tendinopathy in-season? A randomised clinical trial. Journal of science and medicine in sport, 19(9), 702-706

Vaquero-Picado, A., Barco, R., \& Antuña, S. A. (2017). Lateral Epicondylitis of the Elbow. EFORT Open Reviews, 1(11), 391-397. Doi:10.1302/2058-5241.1.000049

Waugh, E. J., Jaglal, S. B., Davis, A. M., Tomlinson, G., \& Verrier, M. C. (2004). Factors Associated with Prognosis of Lateral Epicondylitis After 8 Weeks of Physical Therapy. Archives of Physical Medicine and Rehabilitation, 85(2), 308-318 Doi:10.1016/s0003-9993(03)00480-5.

Weber, C., Thai, V., Neuheuser, K., Groover, K., \& Christ, O. (2015). Efficacy of Physical Therapy for the Treatment of Lateral Epicondylitis: A Meta-Analysis. $B M C$ Musculoskeletal Disorders, 16, 223. Doi:10.1186/s12891-015-0665-4

Wen, D. Y., Schultz, B. J., Schaal, B., Graham, S. T., \& Kim, B. S. (2011). Eccentric Strengthening for Chronic Lateral Epicondylosis: A Prospective Randomized Study. Sports Health, 3(6), 500-503. Doi: $10.1177 / 1941738111409690$

How to cite this article: Şavkın, R. and Şimşek, Ş. (2021). Comparison of the Supervised and Home-Based Physiotherapy Program in Patients with Lateral Epicondylitis. Int $\mathrm{J}$ Disabil SportsHealth Sci;4(2):124-129. https://doi.org/10.3343/ ijdshs. 978993 